\title{
Assessment of airway inflammation in children with acute asthma using induced sputum
}

\author{
S.H. Twaddell, P.G. Gibson, K. Carty, K.L. Woolley, R.L. Henry
}

Assessment of airway inflammation in children with acute asthma using induced sputum. S.H. Twaddell, P.G. Gibson, K. Carty, K.L. Woolley, R.L. Henry. ( ERS Journals Ltd 1996.

ABSTRACT: The aims of this study were: to assess the safety of a sputum induction method using inhaled normal saline in children with acute asthma; and to investigate changes in sputum cell counts between acute exacerbations of asthma and its resolution.

Ultrasonically nebulized normal saline was used to induce sputum from children $(n=8)$ presenting with acute asthma within $1 \mathrm{~h}$ of arrival and again at least 14 days later, after resolution of the exacerbation. Children received pretreatment with bronchodilator, and peak expiratory flow (PEF) was monitored throughout the procedure. Samples were analysed for total cell count, differential cell counts, and for eosinophils and neutrophils using specific immunochemical stains.

Sputum induction was performed without adverse effect in each child with acute asthma. The mean fall in PEF from baseline during sputum induction was 5.3\% during the acute attack and $3.4 \%$ at resolution. A shorter nebulization time was required to induce sputum in acute asthma than at follow-up $(7.8 \mathrm{vs} 13.9 \mathrm{~min}$; $\mathbf{p}=0.04)$. During acute asthma, there was an intense cellular infiltrate (mean total cell count $34 \times 10^{6}$ cells $\left.\cdot \mathrm{mL}^{-1}\right)$, which resolved after recovery $\left(1.9 \times 10^{6}\right.$ cells $\left.\cdot \mathrm{mL}^{-1}\right)(\mathrm{p}=\mathbf{0 . 0 4})$. The infiltrate was heterogenous, comprising eosinophils $\left(6.7 \times 10^{6}\right.$ cells $\left.\cdot \mathrm{mL}^{-1}\right)$, neutrophils $\left(5.4 \times 10^{6}\right.$ cells $\left.\cdot \mathrm{mL}^{-1}\right)$ and mast cells $\left(0.47 \times 10^{6}\right.$ cells $\left.\cdot \mathrm{mL}^{-1}\right)$. Resolution of the exacerbation was accompanied by a significant fall in eosinophils and neutrophils $(\mathrm{p} \leq \mathbf{0 . 0 4})$

Normal saline induction of sputum can be used to assess airway inflammation in acute asthma. Children with acute asthma have intense airway inflammation that is heterogeneous and involves neutrophils, eosinophils and mast cells.

Eur Respir J., 1996, 9, 2104-2108.
Airway Research Centre, Respiratory Medicine Unit, John Hunter Hospital, Newcastle, and Discipline of Paediatrics, Faculty of Medicine \& Health Sciences, University of Newcastle, Callaghan, NSW, Australia.

Correspondence: P.G. Gibson

Airway Research Centre

Respiratory Medicine Unit

John Hunter Hospital

Locked Bag 1

Hunter Region Mail Centre

Newcastle

NSW

Australia 2310

Keywords: Asthma

children

eosinophil

neutrophil

sputum

Received: October 121995

Accepted after revision June 201996

This study was supported by the Asthma Foundation of NSW, and National Health and Medical Research Council of Australia.
Airway inflammation is now a widely-accepted feature of asthma, and is typically characterized by airway mucosal infiltration with eosinophils [1-4] and mast cells $[2,3]$, and by T-lymphocyte activation [4]. Neutrophils are seldom involved. This view has arisen largely from studies of adults with mild asthma, who were either stable [2] or had an exacerbation induced by experimental allergen challenge [1]. Studies of airway inflammation in children and in acute asthma are limited. The pattern and severity of airway inflammation in children with acute asthma may differ from that reported in adults with stable asthma, since the severity of the exacerbation is greater and the stimuli for an exacerbation of acute severe asthma are different and include viral respiratory tract infections [5]. In support of this, SuR et al. [6] have recently reported that acute severe asthma is associated with neutrophilic airway inflammation. These observations contrast directly with studies in mild asthma, which fail to identify a role for neutrophilic inflammation [2].

Recently, the induction of sputum with hypertonic saline has been successfully used to study airway inflammation in asthma $[7,8]$. Induced sputum from children with stable asthma also demonstrates an increase in eosinophils and mast cells, with no significant alteration in neutrophil counts $[7,9]$. The severity of airway obstruction is a potential problem with sputum induction in acute asthma. Hypertonic saline inhalation may provoke airway narrowing. This is usually prevented by $\beta_{2}$-agonist pretreatment [7-9]. We hypothesized that the use of normal saline with $\beta_{2}$-agonist protection could be a safe way to induce sputum in children with acute asthma.

The purpose of this study was to examine the safety of using induced sputum to obtain airway samples in children with acute asthma, and to examine the pattern and severity of airway inflammation in this setting.

Materials and methods

\section{Subjects}

The study involved children aged 8-15 yrs, who presented to the Paediatric Emergency Department of the John 
Hunter Hospital with acute asthma. The study was approved by the Human Research Ethics Committee of the University of Newcastle and by the Hunter Area Research Ethics Committee. Written, informed consent was obtained from all parents and children recruited into the study.

\section{Study design}

Children were studied on two occasions, once during the acute asthma presentation (Visit 1) and once again after resolution of the acute attack (Visit 2). A triage nurse assessed children at presentation to the Paediatric Emergency Department and a member of the research team (ST) was contacted to assess children aged 8-15 yrs presenting with a triage diagnosis of asthma, breathlessness or cough. The final diagnosis of asthma was confirmed by the attending medical officer. Children were excluded if they were not seen by the researcher immediately after presentation and prior to receiving nebulizer and corticosteroid treatment. A sputum sample was obtained from each child within $1 \mathrm{~h}$ of arriving. Asthma severity was assessed by the attending medical officer and therapy initiated with oxygen and nebulized salbutamol $(2.5$ or $5 \mathrm{mg}$ ). Peak expiratory flow (PEF) (Wright peak flow meter; Clement Clarke, London, UK) was then measured and, if above $40 \%$ predicted, sputum induction was performed. If PEF was below $40 \%$ pred, nebulized salbutamol was administered until PEF reached $\geq 40 \%$ pred. If PEF was still below $40 \%$ pred after the third nebulization, collection of a spontaneous sputum sample was attempted.

\section{Collection of sputum samples}

Induced sputum samples were obtained using an Omron NE-U06 ultrasonic nebulizer (Omron Corp., Tokyo, Japan; output $1.5 \mathrm{~mL} \cdot \mathrm{min}^{-1}$ ) and the child was instructed to rinse his/her mouth with water and blow his/her nose. Children wore a noseclip and inhaled sterile normal saline (NS) $(0.9 \%)$ via a mouthpiece for $30 \mathrm{~s}, 2$ min and then for successive 4 min periods until a cumulative nebulization time of $20 \mathrm{~min}$ had been achieved. PEF was performed $1 \mathrm{~min}$ after each nebulization period. Supplemental $\beta$-agonist was administered if PEF dropped by more than $10 \%$ from baseline between consecutive measurements, if requested by the patient, or if PEF fell below $40 \%$ of the predicted value.

Subjects were encouraged to cough and expectorate sputum following each dose of saline. Cough followed by throat clearing was demonstrated by the investigator. Children were encouraged to take a deep inhalation, cough and empty any oral contents into a sterile container. Sputum induction was ceased under the following circumstances: when sputum was collected; after $20 \mathrm{~min}$ of nebulization; or immediately if PEF dropped to less than $40 \%$ of predicted.

A follow-up induced sputum sample was collected at least 14 days later (Visit 2) using an identical protocol to Visit 1. The time of day was standardized to avoid possible diurnal variation in sputum cell counts, and the children were pretreated with the same dose of $\beta$-agonist that was administered at Visit 1.

\section{Sputum analysis}

Sputum was analysed by the "selected sample" method as described previously [3, 7, 10]. Sputum was placed in a petri dish and cellular clumps (plugs) were removed from the surrounding saliva using forceps and a positive displacement aspiration pipette. At inverted microscopy, it was possible to identify lower respiratory cells as densely crowded clumps of round cells, some of which were larger with ruffled membranes suggestive of pulmonary macrophages. These were easily distinguished from areas of sparse polygonal cells, which represented saliva and squamous epithelial cells. Smears were prepared [3] and stained with chromotrope 2R (C2R) for eosinophils and acidic toluidine blue following Carnoy's fixation for metachromatic cells (mast cells and basophils). Cell counts were expressed as the percentage of positive cells from 400 nucleated cells in C2R slides and 1,500 cells in toluidine blue stained slides. A $300 \mu \mathrm{L}$ aliquot of sputum plug was dissolved in $2.7 \mathrm{~mL}$ of dithiothreitol at a 1:10 concentration (Sputolysin; Calbiochem Corp., La Jolla, CA, USA) [7, 10]. The solution was then gently rotated for 30-120 min at room temperature, until the sputum plug was completely dispersed in the solution. The solution was passed through a $50 \mu \mathrm{m}$ nylon gauze filter to remove squamous epithelial cells and debris. A $100 \mu \mathrm{L}$ aliquot was removed from the solution, mixed with an equal volume of white blood cell diluting fluid (gentian violet, glacial acetic acid and distilled water) and the total cell count measured using a haemocytometer (Neubauer chamber).

The cell suspension was washed in phosphate-buffered saline and cytocentrifuge preparations prepared (Cytospin 3 cytocentrifuge; Shandon Scientific, UK), and airdried, fixed and stained using the alkaline phosphatase anti-alkaline phosphatase (APAAP) technique [11]. A mouse monoclonal antibody directed at human neutrophil elastase (HNE) (Dako Corp., Carpinteria, CA, USA) was used as a specific neutrophil marker [11]. Eosinophils were detected using an EG2, monoclonal antibody to the secreted form of eosinophil cationic protein (ECP) [10, 12] (Kabi Pharmacia Diagnostics $A B$, Sweden) and the APAAP immunochemical staining technique. Positive controls, isotype (mouse immunoglobulin G1 (IgG1)) and substrate controls were included in these assays. The percentage of positive cells was determined by counting 400 cells in random fields and expressing the number as a percentage of the total.

\section{Analysis}

The data were summarized as mean and SEM. Comparisons of cell counts between the acute presentation (Visit 1) and follow-up (Visit 2) were made using Wilcoxon's signed rank test. PEF values and cumulative nebulizer times at each visit were calculated as arithmetic means and compared using the Student's t-test for paired samples. A p-value of $<0.05$ was considered significant.

\section{Results}

Eight children who presented with acute asthma were recruited into the study (table 1 ). None of the children 
Table 1. - Characteristics of children with acute asthma and follow-up

\begin{tabular}{|c|c|c|c|c|c|c|c|}
\hline $\begin{array}{l}\text { Subject } \\
\text { No. }\end{array}$ & $\begin{array}{l}\text { Age } \\
\text { yrs }\end{array}$ & Sex & $\begin{array}{l}\text { Admitted to } \\
\text { hospital? }\end{array}$ & CS use ${ }^{+}$ & $\begin{array}{c}\text { Duration of acute } \\
\text { exacerbation } \\
\mathrm{h}\end{array}$ & $\begin{array}{c}\text { Acute asthma } \\
\text { PEF } \\
\% \text { pred }\end{array}$ & $\begin{array}{c}\text { Follow-up } \\
\text { PEF } \\
\% \text { pred }\end{array}$ \\
\hline 1 & 12 & M & No & Nil & 21 & 56 & 118 \\
\hline 2 & 11 & M & No & Oral & 120 & 96 & 96 \\
\hline 3 & 10 & M & Yes & Nil & 12 & 40 & 92 \\
\hline 4 & 12 & $\mathrm{~F}$ & Yes & Inhaled & 15 & 25 & 96 \\
\hline 5 & 14 & $\mathrm{~F}$ & Yes & Oral, inhaled & 72 & 86 & 89 \\
\hline 6 & 11 & $\mathrm{~F}$ & Yes & Inhaled & 48 & 58 & 88 \\
\hline 7 & 11 & $\mathrm{M}$ & Yes & Inhaled & 24 & 39 & 95 \\
\hline 8 & 13 & $\mathrm{~F}$ & Yes & Oral, inhaled & 5 & 95 & NA \\
\hline Mean & 12 & & & & 40 & 62 & $96^{*}$ \\
\hline SEM & 1 & & & & 14 & 10 & 4 \\
\hline
\end{tabular}

+: corticosteroid use at time of initial presentation. NA: data not available; M: male; F: female; CS: corticosteroid; PEF: peak expiratory flow; $\%$ pred: percentage of predicted value. $*$ : $\mathrm{p}<0.05$, follow-up $v s$ acute asthma.

were treated with antibiotics, and no lung infiltrate was present in the six children who had a chest radiograph. No child had a temperature recorded above $38^{\circ} \mathrm{C}$, although four children had a temperature of $>37.5^{\circ} \mathrm{C}$. The attending physician recorded a respiratory tract infection as the precipitant of the asthma attack in five children (Nos. 2-4, 6, 7). Three children had a background history of infrequent episodic asthma (Nos. 1-3), one had frequent episodic asthma (No. 4), and four had persistent asthma (Nos. 5-8). Each of the six children who underwent sputum induction at presentation produced a sputum sample. Spontaneous samples were obtained from the other two children (Nos. 4 and 7) who had PEF values below $40 \%$ pred. Seven children were available for a follow-up visit, and all children required saline induction in order to obtain a sputum sample. Six of the seven children who attempted sputum induction at the follow-up visit were successful.

\section{Safety of sputum induction}

The safety of sputum induction in acute asthma was assessed by recording PEF at baseline prior to sputum induction and then recording PEF periodically throughout the procedure (table 2 and fig. 1). Each child completed the sputum induction without adverse effect. During the acute presentation, the baseline PEF was reduced and the average time to obtain a satisfactory sputum sample was less than at resolution (7.8 vs 13.9 min; $\mathrm{p}<0.05)$. The maximum recorded fall in PEF during

Table 2. - Sputum induction in children during acute asthma compared with follow-up $(n=6)^{*}$

\begin{tabular}{|c|c|c|c|}
\hline & Acute asthma & Follow-up & p-value \\
\hline Baseline PEF \% pred & $66(9.7)$ & $96(3.8)$ & 0.01 \\
\hline Fall in $\mathrm{PEF}^{\dagger} \%$ & $5.3(1.3)$ & $3.4(1.2)$ & NS \\
\hline $\begin{array}{l}\text { Cumulative nebulization } \\
\text { time } \min \end{array}$ & n $7.8(1.7)$ & $13.9(2.0)$ & 0.04 \\
\hline $\begin{array}{l}\text { Satisfactory sample } \\
\text { obtained }\end{array}$ & $6 / 6^{*}$ & $6 / 7$ & NS \\
\hline
\end{tabular}

Values are presented as mean, with SEM in parenthesis. *: spontaneous sputum samples were produced by two children at the initial visit. $\dagger$ : from baseline during sputum induction. NS: not significant; PEF: peak expiratory flow; $\%$ pred: percentage of predicted value. sputum induction ranged $0-8 \%$ at Visit 1 and $0-10 \%$ at Visit 2.

\section{Sputum cell counts}

At presentation with acute asthma, sputum total cell counts were very high with a mean total cell count of $34 \times 10^{6} \cdot \mathrm{mL}^{-1}$ (fig. 2). At follow-up, the total cell count had decreased significantly to $1.9 \times 10^{6} \cdot \mathrm{mL}^{-1}(\mathrm{p}=0.04)$. There was a heterogeneous cellular infiltrate comprising eosinophils, mast cells and neutrophils. Sputum eosinophil counts were high at presentation and decreased at follow-up visit ( $\mathrm{p}=0.04$ ) (fig. 2). Sputum mast cells (fig. 3 ) also tended to decrease with resolution of the exacerbation $(\mathrm{p}=0.06)$. At presentation with acute asthma, neutrophils were present in similar number to eosinophils and these also decreased at follow-up ( $\mathrm{p}=0.03$ ) (fig. 3). Induced sputum samples at exacerbation contained a mean (SEM) of $3.5(0.6)$ plugs, which was comparable to the number of sputum plugs present in the follow-up samples (5.5 (2.09); $\mathrm{p}=0.68)$.

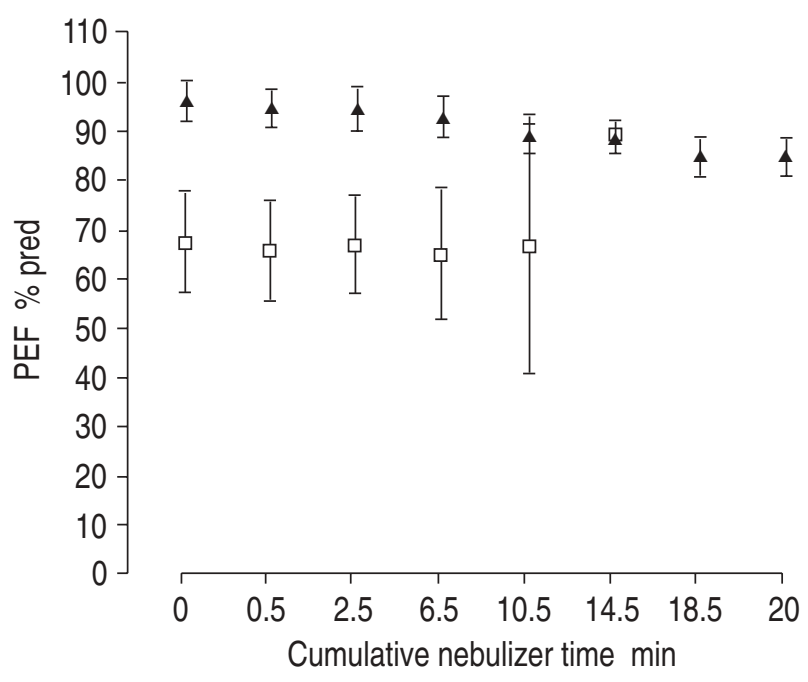

Fig. 1. - Peak expiratory flow (PEF) during sputum induction with ultrasonically nebulized saline in children with acute asthma (open squares) and at follow-up (closed triangles). A shorter nebulization time was required to obtain sputum samples during acute asthma than at follow-up $(\mathrm{p}<0.05)$. Error bars represent SEM. \% pred: percentage of predicted value. 


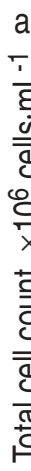

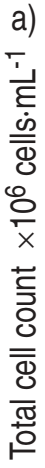
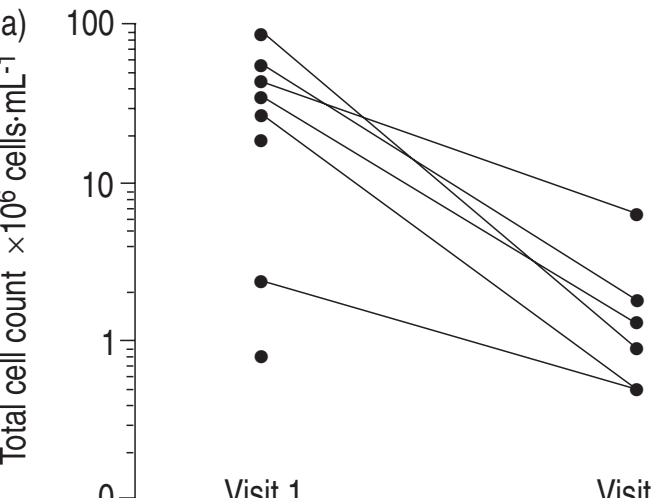

Visit 1

Visit 2
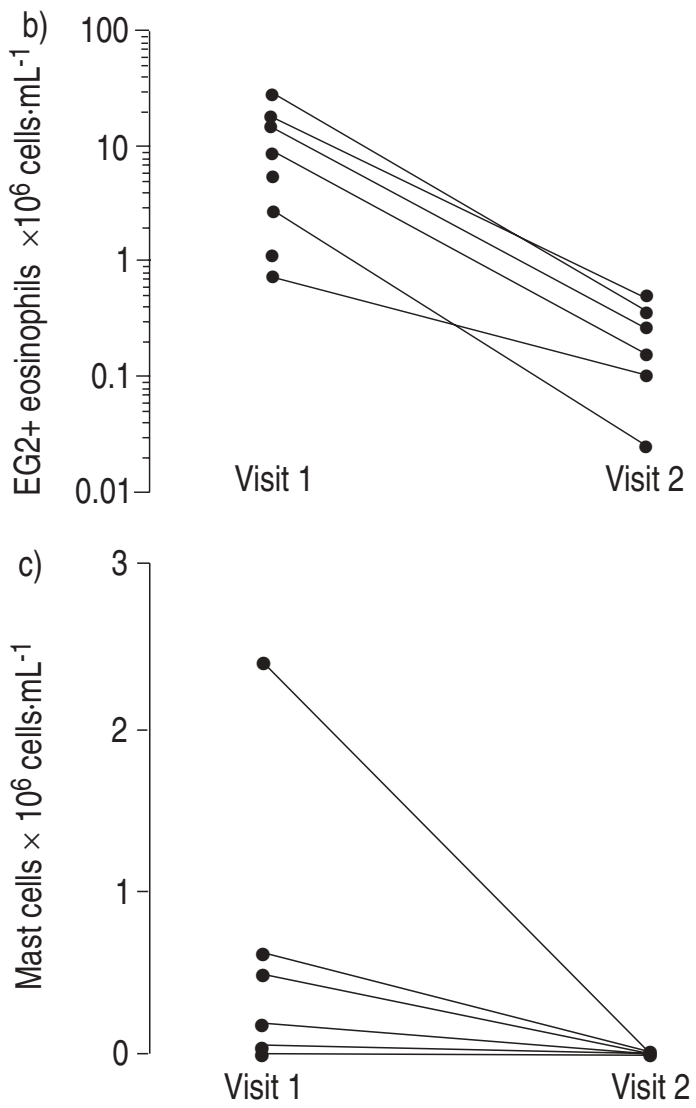

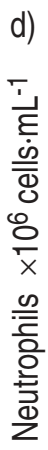

100
10
1
0.1
0.01

Visit 1

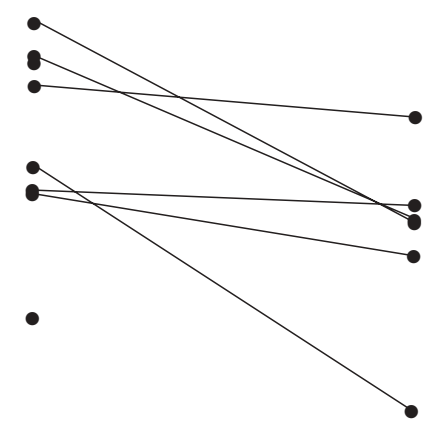

Visit 2

Fig. 2. - a) Sputum total cell counts; b) eosinophils (EG2+ cells); c) sputum mast cells; and d) neutrophils during acute asthma (Visit 1) and follow-up (Visit 2). A significant decrease in the total cell count and eosinophil count occurred between Visits 1 and $2(\mathrm{p}<0.05)$.
The severity of airflow obstruction at presentation (PEF $\%$ pred) was significantly correlated with the intensity of the eosinophil infiltrate $(\mathrm{r}=-0.7 ; \mathrm{p}<0.05)$ but not with neutrophils $(\mathrm{r}=-0.25 ; \mathrm{p}>0.05)$. Mast cell numbers were closely correlated with eosinophil numbers $(r=0.98$, $\mathrm{p}<0.05$ ).

\section{Discussion}

This study has established that sputum can be induced for assessment of airway inflammation in children presenting with acute asthma, and that these children demonstrate intense airway inflammation with a heterogeneous cell profile comprising eosinophils, neutrophils and mast cells. The use of induced sputum proved to be a safe and useful technique for studying airway inflammation in children with acute asthma. Resolution of the asthma exacerbation was associated with a reduction in each of the inflammatory cell types. In children with acute asthma, airway inflammation was both more intense and the cell profile was more heterogenous than that previously reported for stable asthma in children and adults.

Induced sputum analysis is attractive as a noninvasive means to assess airway inflammation in asthma. Previous problems with sputum analysis have included the inability to obtain samples when required, and poor reproducibility of results. These problems have been overcome by the use of sputum induction [7, 8] and quantitative cytology [3]. Using hypertonic saline inhalation, sputum can be induced from most adults and children (over 8 yrs). A standardized processing technique provides good reproducibility $[3,7,10]$ and induced sputum cell counts correlate with results from bronchial washings obtained at bronchoscopy [13]. With the use of an adequate cell dispersion technique, cell counts are reproducible between sputum plugs [3], and over time [3, 7]. Several plugs from the same sample are used in order to minimize the variability within the sample $[3,7]$.

This study demonstrates that sputum induction can also be used in the setting of acute asthma. We used normal saline inhalation to induce sputum for analysis because it was considered less likely to provoke bronchoconstriction in acute asthma. The results indicate that sputum induction was well tolerated by children with acute asthma, provided that certain precautions were observed. Beta-agonist premedication was used to block bronchoconstriction, subjects used supplemental oxygen, and peak expiratory flow was monitored throughout the procedure. A medical practitioner was in attendance, and the test was terminated at a preset level of airflow obstruction. A shorter cumulative nebulization time was required to induce sputum during the acute presentation. This suggests that the underlying severity of asthma was a determinant of the success of sputum induction. Other features which are known to influence the success of sputum induction include the tonicity of the saline used [14], and the type of nebulizer. Ultrasonic nebulizers give a higher success than jet nebulizers, presumably because they deposit a higher dose of saline in the airway.

The sputum processing method which was used in this study relies upon the selection of lower respiratory material for analysis. This can be readily identified using inverted microscopy to separate cellular clumps containing pulmonary macrophages from surrounding saliva. 
These cellular clumps remain intact and are not dispersed by normal saline [3]. Hence, the cell counts are unlikely to be affected by dilution from differing doses of the saline which was used to induce the samples. It would be useful to confirm this in future studies, and also to compare processing of selected sputum plugs $[3,7]$ with an alternative method which uses the total sample for analysis [8].

Airway inflammation has emerged as an important pathophysiological feature of asthma. A large number of studies have been performed on adults with mild asthma but studies in children are limited. These studies indicate that there is a selective increase in eosinophils and mast cells in stable asthma [3, 7,9]. The total cell count and neutrophil counts are generally not altered in stable asthma or mild exacerbations of asthma. Our findings suggest that the intensity and pattern of airway inflammation in children with acute asthma may be different to that of children with stable asthma. The sputum total cell count, an indicator of the intensity of airway inflammation, was fourfold greater than that reported in stable asthma [7]. This intense cellular infiltrate reflects the severity of the disease at the time that sputum was obtained, since sputum total cell counts returned to previously reported levels with resolution of the asthma exacerbation. The pattern of inflammation was heterogeneous and included neutrophils as well as eosinophils and mast cells. Further work is needed to confirm these observations and investigate the mechanism of the intense cellular infiltrate and altered cell profile in acute childhood asthma.

In conclusion, induced sputum is a safe and useful technique for assessing airway inflammation in children with acute asthma who demonstrate intense airway inflammation involving eosinophils, mast cells and neutrophils.

Acknowledgements: The authors thank G. Sheather who provided secretarial assistance.

\section{References}

1. Metzger WJ, Zavala D, Richerson HB, et al. Local allergen challenge and bronchoalveolar lavage of allergic asthmatic lungs: description of the model and local airway inflammation. Am Rev Respir Dis 1985; 135: 433-440.
2. Kirby JG, Hargreave FE, Gleich GJ, O'Byrne PM. Bronchoalveolar cell profiles of asthmatic and nonasthmatic subjects. Am Rev Respir Dis 1987; 136: 379-383.

3. Gibson PG, Girgis-Garbardo A, Morris MM, et al. Cellular characteristics of sputum from patients with asthma and chronic bronchitis. Thorax 1989; 44: 693-699.

4. Robinson DS, Hamid Q, Ying S, et al. Predominant Th2like bronchoalveolar T-lymphocyte population in atopic asthma. N Engl J Med 1992; 326: 298-304.

5. Carlsen KH, Orstavik I, Leegaard J, Hoeg H. Respiratory virus infections and aeroallergens in acute bronchial asthma. Arch Dis Child 1984; 59: 310-315.

6. Sur S, Crotty TB, Kephart GM, et al. Sudden-onset fatal asthma: a distinct entity with few eosinophils and relatively more neutrophils in the airway submucosa? Am Rev Respir Dis 1993; 148: 713-719.

7. Pin I, Gibson PG, Kolendowicz R, et al. Use of induced sputum cell counts to investigate airway inflammation in asthma. Thorax 1992; 47: 25-29.

8. Fahy JV, Liu J, Wong H, Boushey HA. Cellular and biochemical analysis of induced sputum from asthmatic and from healthy subjects. Am Rev Respir Dis 1993; 147: 1126-1131.

9. Pin I, Radford S, Kolendowicz R, et al. Airway inflammation in symptomatic and asymptomatic children with methacholine hyperresponsiveness. Eur Respir J 1993; 6: 1249-1256.

10. Popov T, Gottschalk R, Kolendowicz R, Dolovich J, Powers P, Hargreave FE. The evaluation of a cell dispersion method of sputum examination. Clin Exp Allergy 1994; 24: 778-783.

11. Pulford KAF, Erber WA, Crick JA, et al. Use of monoclonal antibody against human neutrophil elastase in normal and leukaemic myeloid cells. J Clin Pathol 1988; 4: 853-860.

12. Tai PC, Spry CJF, Peterson C, Verge P, Olson I. Monoclonal antibodies distinguish between storage and secreted forms of eosinophil cationic protein. Nature 1984; 309: 182-184.

13. Fahy JV, Wong HH, Liu J, Boushey HA. Comparison of samples collected by sputum induction and bronchoscopy from asthmatic and healthy subjects. Am J Respir Crit Care Med 1995; 152: 53-58.

14. Bacci E, Carnevali S, Cianchetti S, et al. Comparison between hypertonic saline and normal saline induced sputum in asthmatic subjects. Am J Respir Crit Care Med 1994; 149: A571. 